\title{
Association Between Alcohol Use and HIV-Related Sexual Risk Behaviors Among Men Who Have Sex with Men (MSM): Findings from a Multi-Site Bio-Behavioral Survey in India
}

\author{
Diwakar Yadav • Venkatesan Chakrapani • Prabuddhagopal Goswami • \\ Shreena Ramanathan • Lakshmi Ramakrishnan • Bitra George • Shrabanti Sen • \\ Thilakavathi Subramanian · Harikumar Rachakulla $\cdot$ Ramesh S. Paranjape
}

Published online: 24 January 2014

(C) The Author(s) 2014. This article is published with open access at Springerlink.com

\begin{abstract}
This paper examines the association between alcohol use and HIV-related sexual risk behaviors among men who have sex with men (MSM). A cross-sectional biobehavioral survey was conducted among 3,880 MSM, recruited using time-location cluster sampling from cruising sites in three Indian states. Nearly three-fifths of the participants reported alcohol use. Among frequent users (40\% of the sample), defined as those who consumed alcohol daily or at least once a week, $66 \%$ were aged 25 years and above, $53 \%$ self-identified as kothi (feminine/receptive), and $63 \%$ consistently used condoms with male paying partners. Multivariate logistic regression demonstrated that frequent users were more likely to be aged 25 years and above, less likely to self-identify as kothi, and less likely to consistently use condoms with male paying ( $\mathrm{AOR}=0.7 ; 95 \% \mathrm{CI} 0.5-0.9$ ) and male regular $(\mathrm{AOR}=0.7 ; 95 \%$ CI $0.6-0.9)$ partners. HIV prevention interventions for MSM need to provide tailored
\end{abstract}

D. Yadav $(\bowtie) \cdot$ P. Goswami $\cdot$ S. Ramanathan .

L. Ramakrishnan $\cdot$ B. George $\cdot$ S. Sen

FHI 360, H-5 (Ground Floor), Green Park Extension,

New Delhi 110016, India

e-mail: yadavdiwakar7@gmail.com; diwakaryadav@fhi360.org

V. Chakrapani

Centre for Sexuality and Health Research and Policy

(C-SHaRP), Chennai, India

T. Subramanian

National Institute of Epidemiology, Chennai, India

H. Rachakulla

National Institute of Nutrition, Hyderabad, India

R. S. Paranjape

National AIDS Research Institute, Pune, India information on alcohol use-related sexual risk, especially for MSM in sex work and MSM with male regular partners.

Keywords Alcohol use $\cdot$ Sexual risk $\cdot$ Condom use $\cdot$ Men who have sex with men $\cdot$ MSM $\cdot$ HIV $\cdot$ India

\section{Introduction}

Men who have sex with men (MSM) are categorized as a high-risk group for HIV by India's National AIDS Control Organisation [1]. The national average HIV prevalence among MSM is $7.4 \%$, about 20 times higher than the average for the general population $(0.31 \%)$; one HIV sero surveillance site reported HIV prevalence among MSM as high as $15 \%$ [2]. Such high HIV prevalence among MSM in India is primarily attributed to unprotected sex with multiple male and female partners [3]. Therefore, identifying and addressing risk factors that facilitate unprotected sex among MSM are vital to HIV prevention. Alcohol use is one such factor.

Alcohol use and its association with HIV-related sexual risk is well documented by studies in other countries [4-7], including studies on MSM [8-11]. Studies in India have found alcohol use to be associated with HIV-related sexual risk across a range of male populations - married men [12], male migrant workers [13], men from low income communities [14], male clients of female sex workers (FSWs) [15], and male patrons of wine shops [16]. However, little information is available on alcohol use among Indian MSM and its association with HIV-related sexual risk.

The available data shows relatively high prevalence of alcohol use among Indian MSM. The National Behavioral Sentinel Surveillance Survey among at-risk groups in India found alcohol use (at least once a week) to be relatively 
high among MSM (36\%), compared with FSWs (15\%) and male clients of FSWs (13\%) [17]. Similarly, crosssectional studies across India have demonstrated high prevalence of alcohol use among MSM, ranging from 4 to $28 \%$ [18-21].

Qualitative studies on Indian MSM have documented lack of condom use during anal sex under the influence of alcohol $[22,23]$. At the time of writing this paper, only two quantitative studies $[18,24]$ on Indian MSM-one from Chennai and another from Mumbai-had explicitly reported findings associating alcohol use with sexual risk, but both did not find any significant association between alcohol use and sexual risk with male partners. The study on MSM in Chennai showed a significant association between weekly alcohol use to the point of being "buzzed/ drunk" and unprotected sex with female partners, but not with male partners [18], while the Mumbai study could not find a statistically significant association between alcohol dependence and consistent condom use with male partners [24]. Also, these single-site studies had no information on biological proxy indicators of sexual risk-prevalence of HIV and sexually transmitted infections (STIs).

In order to address these gaps and contribute to the development of strategies that target alcohol-related sexual risk among MSM, we analyzed data from a bio-behavioral survey conducted among multi-site community-based samples of MSM. In this paper, we describe the prevalence and patterns of alcohol use among MSM and its association with HIV-related sexual risk behaviors, especially consistent condom use with male paying, regular and paid partners and female regular partners.

\section{Methods}

\section{Data Source}

Data for this analysis was drawn from the second round of a series of cross-sectional surveys, termed integrated behavioral and biological assessment, conducted in 2009-2010. The surveys were part of the evaluation of a comprehensive HIV prevention program-Avahan: the India AIDS Initiative, funded by the Bill and Melinda Gates Foundation and implemented in India's four southern (Tamil Nadu, Andhra Pradesh, Karnataka and Maharashtra) and two north-eastern (Nagaland and Manipur) states. For this paper, we restricted the analysis to the three southern states of Andhra Pradesh, Tamil Nadu and Maharashtra. The overall design of the survey has been described in detail elsewhere [25, 26]. In order to obtain a representative sample (3,880 MSM) from cruising sites such as parks, public toilets, bus stands and local train stations, we used a two-stage time-location cluster sampling (TLCS) procedure. In general, TLCS is used to recruit hard-to-reach populations, including highrisk MSM [27, 28]; it has been used in other studies on Indian MSM [21, 29]. In the two-stage TLCS procedure adapted for the present study, primary sampling units (cruising sites) were selected in the first stage with probability-proportional-to-estimated-size of the MSM population visiting the cruising sites. Potential participants who were aged 18 years or older and had had any kind of sex (oral or anal) with other men in the past month were identified in the second stage through systematic random sampling to recruit eligible and willing persons.

Behavioral data were collected through an intervieweradministered questionnaire in three Indian languages (Tamil, Telugu and Marathi), and blood and urine samples were tested for HIV and STIs. Written informed consent was obtained from the participants. The Health Ministry Screening Committee of the Indian Council of Medical Research (ICMR) and local ethical committees of the implementing institutes of ICMR (National AIDS Research Institute, Pune; National Institute of Nutrition, Hyderabad; and National Institute of Epidemiology, Chennai), and the Protection of Human Subjects Committee of FHI 360 approved the study protocol.

\section{Measures}

\section{Alcohol Use}

Participants were asked how often they had consumed alcohol in the past month, for which the response options were: every day/daily, at least once a week, less than once a week, not in the past month or never consumed. We categorized the MSM who reported consuming alcohol daily or at least once a week as 'frequent' users of alcohol. Those reporting alcohol consumption of less than once a week, not in the past month, or never consumed were categorized as 'non-/infrequent' users of alcohol. This categorization was based on the opinion of MSM community leaders, who believed that a man regularly drinking alcohol at least once a week can be labeled as a 'frequent' user of alcohol (since social drinking is less likely to take place every week in this context, where the sample predominantly comes from the lower socioeconomic group). Also, the previous studies on Indian MSM used a similar categorization- 'weekly alcohol users' [18] and alcohol consumption '<once per week vs.> once per week' [19]. While specific scales for alcohol consumption, such as the Alcohol Use Disorders Identification Test [30], are available, we used the relatively simple selfreported measure of frequency of alcohol drinking, since that information was collected as part of this study focusing on HIV-related risk among MSM. Notably, this paper provides new information on the prevalence and correlates of alcohol 
use and its association with sexual risk behavior among MSM.

\section{Sociodemographic Characteristics}

Participants were asked about their current age, literacy level, employment status, marital status and self-identity (such as, kothi, double-decker, panthi and hijra). Selfidentities among MSM are usually based on gender expression and sexual role: kothis are usually feminine and receptive, panthis are masculine and insertive [31, 32], and double-deckers are both insertive and receptive [33]. Although hijras belong to a distinct sociocultural group and can be regarded as male-to-female transgender persons, they were included under the 'MSM' umbrella for this analysis because of their relatively small sample size in this study (2.5\% of the total sample).

\section{Consistency in Condom Use with Different Types of Male and Female Partners}

Participants were asked how often they used condoms during anal (or vaginal) sex with different types of male and female partners. For the purposes of the survey, the different types of partners were operationally defined as(1) regular partner: the main partner to whom the participant feels committed to, such as spouse or lover; (2) paying partner: the person who paid the participant in cash or kind in exchange for sex; (3) casual partner: a stranger, friend or acquaintance with whom the participant had sex but did not consider that person as a regular or paying partner; (4) paid partner: the person to whom the participant paid in cash or kind for having sex.

\section{Self-Risk Perception and Exposure to HIV Intervention}

The survey covered information on self-risk perception of acquiring HIV infection and exposure to HIV intervention. A composite indicator of the participants' exposure to HIV intervention was created: participants were classified as having been exposed to HIV intervention if in the previous year they had received any of the three core program services-(1) contacted by a peer educator/outreach worker, (2) received condoms from outreach workers, or (3) visited an STI clinic-from a nongovernmental organization working with MSM.

\section{Current Membership in a Community-Based Organization}

The participants were asked if they were members of a community-based organization (CBO), that is, an agency that is formed and managed by self-identified MSM.

\section{Prevalence of STIs and HIV}

Blood and urine samples were collected and tested for HIV and other STIs. Syphilis was screened by the rapid plasma reagin test and confirmed by treponema pallidum hemagglutination assay. Nucleic-acid amplification (Gen-Probe APTIMA Combo 2 by Gen-Probe Inc., San Diego, California) tests were conducted to screen for chlamydial and gonococcal infections. HIV-seropositivity was determined through a two-test algorithm using enzyme immunoassay (J. Mitra EIA Kit). Participants who tested positive for any one of the three STIs (syphilis, gonorrhoea and chlamydiasis) were categorized as 'having any STIs'.

\section{Data Analysis}

Bivariate analyses (Chi square tests) examined the relationship between alcohol consumption and sociodemographic and sexual risk behavior variables. Multivariate logistic regression was conducted to assess the degree of association between frequent alcohol consumption and sociodemographic characteristics and other contextual factors, including consistency in condom use with different types of male and female partners, exposure to any HIV prevention intervention, current membership in a CBO, and 'having any STIs' or HIV. Associations were considered significant for $p$-values less than 0.05 at $95 \%$ confidence interval. Analyses were conducted in Stata version 12.0 [34].

For logistic regression analyses, some variables that initially had three or more categories were collapsed into meaningful binary categories to aid interpretation of results, especially if there were very low frequencies in certain categories of those variables. Hence, age group was categorized as '18-24 years' and '25 years and above'; educational qualification as 'illiterate' and 'literate'; and marital status as 'never married' and 'ever married'. For occupational status, we categorized participants into two groups: 'unemployed/student' and 'employed', with the latter including self-employed, nonagricultural labor and government/private employees. Since kothis are generally more visible, well organized and have relatively better access to interventions than other MSM subgroups [35], we categorized the self-identities of MSM as 'kothis' and 'non-kothis', with the latter including panthis, doubledeckers and bisexual-identified MSM.

We used exploratory logical model building in this study. The covariates included in multivariate logistic models were selected based on the available literature on correlates of alcohol and condom use (for example, HIV risk perception), and assumptions based on discussion with HIV program people (for example, exposure to HIV prevention intervention and current membership in an MSM 
Table 1 Proportion of MSM who are frequent and non-/infrequent users of alcohol by background, sexual risk and other characteristics (Integrated Behavioral and Biological Assessment Survey; 2009-10)

\begin{tabular}{|c|c|c|c|c|c|}
\hline \multirow[t]{2}{*}{ Characteristics } & \multirow[t]{2}{*}{ Percent } & \multicolumn{2}{|c|}{ Alcohol use in the previous month } & \multicolumn{2}{|c|}{ Test of association } \\
\hline & & Frequent users & Non-/infrequent users & Chi square & $p$ value \\
\hline Sample size & 3,880 & 1,535 & 2,345 & & \\
\hline Total \% & 100 & 39.6 & 60.4 & & \\
\hline Age group (in years) & & & & 38.4 & 0.000 \\
\hline Mean (S.D.) & $27.7(7.5)$ & $28.6(7.6)$ & $27.2(7.4)$ & & \\
\hline $18-24$ & $39.4(1,528)$ & 33.4 & 43.3 & & \\
\hline $25-34$ & $42.6(1,655)$ & 46.3 & 40.3 & & \\
\hline 35 and above & $18.0(697)$ & 20.3 & 16.5 & & \\
\hline Education & & & & 22.5 & 0.000 \\
\hline Illiterate & $12.7(495)$ & 14.7 & 11.5 & & \\
\hline Up to 8 th grade & $24.1(936)$ & 26.0 & 22.9 & & \\
\hline 9th-12th grade & $49.8(1,933)$ & 48.3 & 50.8 & & \\
\hline Any college education & $13.3(516)$ & 11.0 & 14.8 & & \\
\hline Occupation & & & & 56.9 & 0.000 \\
\hline Unemployed/student & $10.8(426)$ & 7.6 & 13.1 & & \\
\hline Self-employed & $20.4(794)$ & 22.2 & 19.3 & & \\
\hline Nonagricultural labor & $25.2(981)$ & 26.2 & 24.6 & & \\
\hline Government/private employee & $24.9(969)$ & 22.7 & 26.4 & & \\
\hline Others & $18.3(710)$ & 21.1 & 16.4 & & \\
\hline Marital status & & & & 12.1 & 0.002 \\
\hline Never married & $70.6(2,741)$ & 67.7 & 72.6 & & \\
\hline Currently married & $28.3(1,097)$ & 30.9 & 26.6 & & \\
\hline Widowed/divorced/others & $1.1(42)$ & 1.4 & 0.8 & & \\
\hline Self-identity & & & & 41.6 & 0.000 \\
\hline Kothi (feminine/receptive) & $54.6(2,120)$ & 52.8 & 55.8 & & \\
\hline Panthis (masculine/insertive) & $13.3(516)$ & 11.9 & 14.2 & & \\
\hline Double-deckers (insertive and receptive) & $11.5(446)$ & 10.9 & 11.9 & & \\
\hline Bisexuals & $18.1(7.3)$ & 20.3 & 16.7 & & \\
\hline Hijra & $2.5(95)$ & 4.1 & 1.4 & & \\
\hline Consistent condom use with female regular partner & & & & 5.4 & 0.020 \\
\hline Yes & $14.5(184)$ & 11.7 & 16.4 & & \\
\hline No & $85.5(1,087)$ & 88.3 & 83.6 & & \\
\hline Consistent condom use with male paying partner & & & & 29.7 & 0.000 \\
\hline Yes & $69.6(1,653)$ & 63.3 & 73.8 & & \\
\hline No & $30.4(722)$ & 36.7 & 26.2 & & \\
\hline Consistent condom use with male paid partner & & & & 1.1 & 0.290 \\
\hline Yes & $76.8(447)$ & 74.8 & 78.5 & & \\
\hline No & $23.2(135)$ & 25.2 & 21.5 & & \\
\hline Consistent condom use with male regular partner & & & & 29.9 & 0.000 \\
\hline Yes & $68.1(1,623)$ & 61.5 & 72.2 & & \\
\hline No & $31.9(761)$ & 38.5 & 27.8 & & \\
\hline HIV risk perception & & & & 3.9 & 0.046 \\
\hline No & $75.1(2,915)$ & 73.4 & 76.3 & & \\
\hline Yes & $24.9(965)$ & 26.6 & 23.7 & & \\
\hline Exposure to HIV prevention intervention & & & & 0.6 & 0.432 \\
\hline No & $23.1(895)$ & 22.4 & 23.5 & & \\
\hline Yes & $76.9(2,985)$ & 77.6 & 76.5 & & \\
\hline
\end{tabular}


Table 1 continued

\begin{tabular}{|c|c|c|c|c|c|}
\hline \multirow[t]{2}{*}{ Characteristics } & \multirow[t]{2}{*}{ Percent } & \multicolumn{2}{|c|}{ Alcohol use in the previous month } & \multicolumn{2}{|c|}{ Test of association } \\
\hline & & Frequent users & Non-/infrequent users & Chi square & $p$ value \\
\hline Current membership in a community-based organization & & & & 5.9 & 0.014 \\
\hline No & $42.7(1,656)$ & 45.1 & 41.1 & & \\
\hline Yes & $57.3(2,224)$ & 54.9 & 58.9 & & \\
\hline HIV status & & & & 0.1 & 0.762 \\
\hline HIV-negative & $87.4(3,392)$ & 87.6 & 87.3 & & \\
\hline HIV-positive & $12.6(488)$ & 12.4 & 12.7 & & \\
\hline Any STIs & & & & 0.6 & 0.423 \\
\hline No & $93.2(3,615)$ & 92.8 & 93.4 & & \\
\hline Yes & $6.8(265)$ & 7.2 & 6.6 & & \\
\hline
\end{tabular}

STI sexually transmitted infection, S.D. standard deviation

CBO). Therefore, in general we used both 'inclusion strategy' (inclusion of alternative explanations for any associations) and 'exclusion strategy' (inclusion of control variables and elimination of spuriousness) [36].

\section{Results}

Sociodemographic Characteristics, Alcohol Use and Sexual Risk Behavior

Of the 3,880 MSM who were interviewed, nearly threefifths of the participants were aged 25 years or above. The majority of MSM were literate (88\%), employed (89\%), never married (71\%) and self-identified as kothi (55\%). About two-thirds (69\%) reported having male paying partners and $57 \%$ reported having current membership in an MSM CBO. Nearly three-fourths of the participants had been exposed to HIV prevention intervention. The proportions of MSM with 'any STIs (excluding HIV)' and HIV were 7 and $13 \%$, respectively (see Table 1).

In univariate analyses, nearly three-fifths $(60 \%)$ of the participants reported 'any alcohol use' (use of alcohol every day, at least once a week or less than once a week). About $40 \%$ participants were frequent users, consuming alcohol once a day or at least once a week. The characteristics of frequent users and non-/infrequent users varied (see Table 1). Among frequent users, two-thirds (66\%) were aged 25 years and above, most (85\%) were literate, about a half (53\%) self-identified as kothis, and $78 \%$ had been exposed to any HIV prevention intervention. Compared with non-/infrequent users, a smaller percentage of frequent alcohol users reported consistent condom use with male paying partners (74 vs. $63 \% ; \chi^{2}=29.7 ; p<0.01$ ). A marginally lower proportion of frequent users reported having membership in an MSM CBO, compared with non-/ infrequent users (55 vs. $59 \%, \chi^{2}=5.9 ; p<0.05$ ). The prevalence of HIV (12 vs. $\left.13 \%, \chi^{2}=0.1 ; p=0.76\right)$ and any one of the three STIs ( 7 vs. $7 \%, \chi^{2}=0.6, p=0.4$ ) was marginally lower (but not statistically significant) among frequent users than the non-/infrequent users.

Multivariate Analyses: Predictors of Alcohol Use Among MSM

The results in Table 2 show that frequent users were more likely to be in the age group of 25 years and above $(\mathrm{AOR}=1.3 ; 95 \% \mathrm{CI}=1.1-1.6)$, employed $(\mathrm{AOR}=1.5$; $95 \% \mathrm{CI}=1.2-1.9)$, ever married $(\mathrm{AOR}=1.3 ; 95 \%$ $\mathrm{CI}=1.0-1.7)$, and exposed to any HIV prevention intervention $(\mathrm{AOR}=1.2 ; 95 \% \mathrm{CI}=0.9-1.4)$. However, they were less likely to use condoms consistently with male paying $(\mathrm{AOR}=0.7 ; 95 \% \mathrm{CI}=0.5-0.9)$ or regular $(\mathrm{AOR}=0.7$; $95 \% \mathrm{CI}=0.6-0.9)$ partners, to be a current member of an MSM CBO $(\mathrm{AOR}=0.8 ; 95 \% \mathrm{CI}=0.7-0.9)$, and to have kothi identity $(\mathrm{AOR}=0.7 ; 95 \% \mathrm{CI}=0.6-0.8)$. There was no statistically significant association between frequent alcohol use and being HIV-positive or having any STIs $(\mathrm{AOR}=0.9 ; 95 \% \mathrm{CI}=0.7-1.1)$.

\section{Discussion}

We found a high prevalence of 'any alcohol use' and 'frequent' alcohol use among the MSM in this study, with frequent users reporting higher prevalence of inconsistent condom use with male paying and regular partners. Frequent users were more likely to be above 25 years of age, to have ever been married, and to have had exposure to HIV prevention intervention. Kothi-identified MSM and MSM with membership in a CBO were at decreased odds for frequent use of alcohol. 
Table 2 Association between frequent alcohol use and sociodemographic and sexual risk behaviors among MSM $(n=3,880)$, adjusted for sociodemographic characteristics and exposure to HIV intervention

\begin{tabular}{|c|c|c|}
\hline \multirow[t]{2}{*}{ Variables } & \multicolumn{2}{|c|}{$\begin{array}{l}\text { Frequent alcohol use in the previous } \\
\text { month }\end{array}$} \\
\hline & UOR (95 \% CI) & $\operatorname{AOR}(95 \% \mathrm{CI})$ \\
\hline \multicolumn{3}{|l|}{ Age group (in years) } \\
\hline $18-24$ & 1.0 & 1.0 \\
\hline 25 and above & $1.5(1.3-1.7)^{* * *}$ & $1.3(1.1-1.6)^{* * *}$ \\
\hline \multicolumn{3}{|l|}{ Education } \\
\hline Illiterate & 1.0 & 1.0 \\
\hline Literate & $0.7(0.6-0.9)^{* * *}$ & $0.8(0.6-0.9)^{* *}$ \\
\hline \multicolumn{3}{|l|}{ Occupation } \\
\hline Unemployed/student & 1.0 & 1.0 \\
\hline Employed & $1.8(1.4-2.2)^{* * *}$ & $1.5(1.2-1.9)^{* * *}$ \\
\hline \multicolumn{3}{|l|}{ Marital status } \\
\hline Never married & 1.0 & 1.0 \\
\hline Ever married & $1.2(1.0-1.4)^{* * *}$ & $1.3(1.0-1.7)^{* *}$ \\
\hline \multicolumn{3}{|l|}{ Self-identity } \\
\hline Non-kothi-identified MSM & 1.0 & 1.0 \\
\hline Kothi-identified MSM & $0.8(0.7-1.0)^{*}$ & $0.7(0.6-0.8)^{* * *}$ \\
\hline \multicolumn{3}{|c|}{ Consistent condom use with male paying partner ${ }^{\mathrm{a}}$} \\
\hline No & 1.0 & 1.0 \\
\hline Yes & $0.6(0.5-0.7)^{* * *}$ & $0.7(0.5-0.9)^{* * *}$ \\
\hline \multicolumn{3}{|c|}{ Consistent condom use with male regular partner ${ }^{\mathrm{b}}$} \\
\hline No & 1.0 & 1.0 \\
\hline Yes & $0.6(0.5-0.7)^{* * *}$ & $0.7(0.6-0.9)^{* * *}$ \\
\hline \multicolumn{3}{|c|}{ Consistent condom use with male paid partner ${ }^{\mathrm{c}}$} \\
\hline No & 1.0 & 1.0 \\
\hline Yes & $0.8(0.5-1.9)$ & $1.1(0.7-1.6)$ \\
\hline \multicolumn{3}{|c|}{ Consistent condom use with female regular partner ${ }^{\mathrm{d}}$} \\
\hline No & 1.0 & 1.0 \\
\hline Yes & $0.6(0.4-0.9)^{* * *}$ & $1.0(0.7-1.5)$ \\
\hline \multicolumn{3}{|c|}{ Exposure to HIV prevention intervention } \\
\hline No & 1.0 & 1.0 \\
\hline Yes & $1.0(0.9-1.2)$ & $1.2(0.9-1.4)^{* *}$ \\
\hline \multicolumn{3}{|c|}{ Current membership in a community-based organization } \\
\hline No & 1.0 & 1.0 \\
\hline Yes & $0.8(0.7-0.9)^{* * *}$ & $0.8(0.7-0.9)^{* *}$ \\
\hline \multicolumn{3}{|l|}{ Either HIV or 'any STIs' } \\
\hline No & 1.0 & 1.0 \\
\hline Yes & $1.0(0.8-1.2)$ & $0.9(0.7-1.1)$ \\
\hline
\end{tabular}

UOR unadjusted odds ratio, $A O R$ adjusted odds ratio, $C I$ confidence interval

$* p<0.10 ; * * p<0.05 ; * * * p<0.001$

a Analysis restricted to those who had male paying partners

b Analysis restricted to those who had male regular partners

c Analysis restricted to those who had male paid partners

d Analysis restricted to those who had female regular partners
The prevalence of 'any alcohol use' among the MSM in this sample was nearly thirteen times higher than the national prevalence of 'regular or any alcohol use' in the general population, which ranges 4-7\% [37-39]. Our finding that nearly two-fifths of the MSM were 'frequent users' of alcohol was similar to the observations in other studies among Indian MSM, which had reported 'weekly alcohol use to the point of being buzzed/intoxicated' to be $28 \%$ [18] and 'alcohol dependence/abuse' to be $16.7 \%$ [24].

The other studies, conducted in Chennai and Mumbai, reported higher prevalence of unprotected anal sex during the last sexual encounter with a male partner among MSM who had 'alcohol dependence' [24] and unprotected vaginal sex in the previous 3 months among MSM who were 'weekly alcohol users' [18], respectively. Our findings are consistent with these two studies $[18,24]$. In addition, we found that those who use condoms consistently with male paying and regular partners were less likely to be frequent users of alcohol; such specific information on the male partner type and the association between frequent alcohol use and consistent condom use was previously unavailable.

As we did not collect sexual event-level data on alcohol and condom use in this study, we cannot categorically state that alcohol influenced condom use with male paying and regular partners of frequent alcohol users. Other studies from developed countries have documented that MSM in sex work are often frequent users of alcohol, which increases their chances of being under the influence of alcohol during sex work, and hence the possible influence of alcohol on inconsistent condom use with male paying partners [40-43]. Regarding inconsistent condom use with male regular partners as well, the causal association cannot be proved. Event-level data on the temporal relationship between alcohol and condom use with different types of male and female partners could provide the necessary evidence for or against the influence of alcohol on condom use.

Our finding that MSM aged 25 years and above were more likely to consume alcohol frequently is consistent with other studies from India [18] and developed countries [44, 45]. HIV prevention interventions in India mostly seem to reach the younger MSM population [35]. Having better access to health-related information in general and support of peers could partly explain the relatively lower proportion of frequent alcohol users in the younger age group. Reportedly, the relatively older MSM are largely out of the reach of both MSM CBOs and other MSM in general [35]. In the present study, it is unclear why the frequent users of alcohol are more likely to be aged above 25 years. One possible reason could be that as MSM become older, the number of contacts with their peers may 
decrease and they may not subsequently receive adequate social and psychological support.

Being married to a woman was another independent factor that our study found to be significantly associated with frequent alcohol use; this is consistent with the findings of the study on MSM in Chennai [19]. A qualitative study has documented that once married, many MSM, who previously accessed services from MSM CBOs, decrease their interactions with CBO staff or stop coming to CBOs altogether to avoid discrimination from their peers for marrying a woman [46]. This decreased frequency of contact with HIV intervention/CBO staff and the possible mental health issues related to heterosexual marriage could be linked to frequent alcohol use among married MSM. These findings emphasize the need for providing outreach and HIV-related and psychological support services to married MSM, which could help reduce frequent alcohol use in this population.

We also found that membership in MSM CBOs protected the participants from frequent alcohol use. CBO membership seems to provide the MSM an opportunity to interact with other MSM and receive psychological and emotional support from peers. However, limited information is available on the effects of community membership or collectivization on mental health, alcohol use or consistent condom use among MSM in India [47]. More studies are needed to explore and understand whether and how community-based collectives empower MSM communities, contribute to HIV prevention and protect against risky behaviors such as frequent alcohol use and unprotected sex.

MSM in India experience multiple and complex challenges, including stigmatization and discrimination, which may put them at risk for alcohol use and unprotected sex [23, 48]. Even though identifying the various factors that could contribute to an individual's alcohol consumption pattern may be beyond the scope of HIV prevention intervention projects supported by the government, screening for frequent/problematic alcohol use can be considered in the context of alcohol-related HIV risk.

Our study found that kothi-identified MSM were less likely to frequently use alcohol. HIV interventions in India mainly reach kothi-identified MSM as they are relatively more visible and, in general, willing to visit and use services of CBOs [23, 49]. Compared with other subgroups, kothis are more likely to have a well-connected network with their peers and receive relatively better social and psychological support from one another. In fact, a study from Chennai reported that panthi-identified MSM, who in general are not connected to the social support systems of MSM, were more likely to be 'weekly alcohol users' than kothis [18].

We did not find any statistically significant association between frequent alcohol use and being HIV-positive or having any STIs. One possible reason for this could be that the MSM at study sites, irrespective of their alcohol consumption patterns, had been receiving regular medical check-ups and syndromic management of STIs for nearly 5 years prior to the study [50].

The present study has certain limitations. First, even though we used TLCS, a probability-based sampling technique, to recruit MSM for the study, caution should be exercised in generalizing this study's findings to other MSM populations in India; these findings can primarily be generalized to those MSM who visit cruising sites [51]. Second, like other studies on MSM [18, 24] in India, we did not have information on alcohol use before or during sexual activity; this information would have been useful in providing further evidence on the influence of alcohol on condom use. Third, use of single-item measure of frequency of alcohol use has been shown to be insufficient when compared with AUDIT tool [52]. Also, the 1-month timeframe for this item might have further weakened its psychometric property. Fourth, there was lack of a specific timeframe for measuring consistent condom use with different types of male and female partners, while the frequency of alcohol use had a timeframe (previous one month). Fifth, social desirability bias may have led some participants to underreport their alcohol use and sexual risk behaviors. Despite this possible social desirability bias, we found a statistically significant association between frequent alcohol use and sexual risk in this survey. Despite these limitations, this paper provides program-relevant information on alcohol-related HIV risk behavior among MSM who visit cruising sites. Being a multi-site study and having a larger sample size means it can be better generalized, which is a key strength of this study.

\section{Conclusion}

Our findings have shown that frequent alcohol use is significantly associated with HIV-related risk behaviors among Indian MSM, especially with their male paying and regular partners. The study indicates the need for HIV interventions to screen MSM for alcohol use and establish referral services with alcohol dependence treatment and counseling programs. MSM should be educated about alcohol use-related sexual risk through one-to-one interactions and educational materials. In addition, connecting self-identified MSM with CBOs may help them in accessing the much-needed psychological and social support from other MSM, the lack of which could be a risk factor for alcohol use. Future studies need to use standardized instruments to capture comprehensive information on alcohol consumption (frequency, quantity, ethanol content, intoxication level and bingeing). Also needed are 
studies to understand the reasons behind frequent/problematic alcohol use among MSM and to examine whether and how these reasons are different from those among the general population, given the stigma associated with samesex sexual behavior. Event-level data on alcohol and condom use with different types of male and female partners is also needed to design tailored interventions that address alcohol use-related sexual risk among diverse subgroups of MSM.

Acknowledgments The Bill \& Melinda Gates Foundation funded this research through Avahan: the India AIDS Initiative. The views expressed herein are those of the authors and do not necessarily reflect the official policy or position of the foundation and Avahan. An earlier version of this research paper was presented at the STI \& AIDS World Congress 2013 in Vienna, Austria.

Conflict of interest The authors have no conflict of interest.

Open Access This article is distributed under the terms of the Creative Commons Attribution License which permits any use, distribution, and reproduction in any medium, provided the original author(s) and the source are credited.

\section{References}

1. NACO. National AIDS control programme phase III (2006-2011). New Delhi: Ministry of Health and Family Welfare, Government of India; 2006. p. 244.

2. NACO. NACO Annual Reprot 2011-12. New Delhi: Ministry of Health \& Family Welfare; 2012.

3. WHO-SEARO. HIV/AIDS among men who have sex with men and transgender populations in South-East Asia: the current situation and national responses. Geneva: World Health Organization; 2010. p. 1-149.

4. Shuper PA, Joharchi N, Irving H, Rehm J. Alcohol as a correlate of unprotected sexual behavior among people living with HIV/ AIDS: review and meta-analysis. AIDS Behav. 2009;13:1021-36.

5. Shuper PA, Neuman M, Kanteres F, Baliunas D, Joharchi N, et al. Causal considerations on alcohol and HIV/AIDS - a systematic review. Alcohol Alcohol. 2010;45:159-66.

6. Kalichman SC, Simbayi LC, Kaufman M, Cain D, Jooste S. Alcohol use and sexual risks for HIV/AIDS in sub-Saharan Africa: systematic review of empirical findings. Prev Sci. 2007;8:141-51.

7. Schensul JJ, Singh SK, Gupta K, Bryant K, Verma R. Alcohol and HIV in India: a review of current research and intervention. AIDS Behav. 2010;14(Suppl 1):S1-7.

8. Reisner SL, Mimiaga MJ, Bland S, Skeer M, Cranston K, et al. Problematic alcohol use and HIV risk among Black men who have sex with men in Massachusetts. AIDS Care. 2010;22:577-87.

9. Bruce D, Kahana S, Harper GW, Fernandez MI, ATN. Alcohol use predicts sexual risk behavior with HIV-negative or partners of unknown status among young HIV-positive men who have sex with men. AIDS Care. 2013;25(5):559-65.

10. Folch C, Esteve A, Zaragoza K, Munoz R, Casabona J. Correlates of intensive alcohol and drug use in men who have sex with men in Catalonia, Spain. Eur J Public Health. 2010;20:139-45.

11. Newcomb ME, Clerkin EM, Mustanski B. Sensation seeking moderates the effects of alcohol and drug use prior to sex on sexual risk in young men who have sex with men. AIDS Behav. 2011;15:565-75.
12. Saggurti N, Schensul SL, Singh R. Alcohol use, sexual risk behavior and STIs among married men in Mumbai, India. AIDS Behav. 2010;14(Suppl 1):S40-7.

13. Samet JH, Pace CA, Cheng DM, Coleman S, Bridden C, et al. Alcohol use and sex risk behaviors among HIV-infected female sex workers (FSWs) and HIV-infected male clients of FSWs in India. AIDS Behav. 2010;14(Suppl 1):S74-83.

14. Singh SK, Schensul JJ, Gupta K, Maharana B, Kremelberg D, et al. Determinants of alcohol use, risky sexual behavior and sexual health problems among men in low income communities of Mumbai, India. AIDS Behav. 2010;14(Suppl 1):S48-60.

15. Madhivanan P, Hernandez A, Gogate A, Stein E, Gregorich S, et al. Alcohol use by men is a risk factor for the acquisition of sexually transmitted infections and human immunodeficiency virus from female sex workers in Mumbai, India. Sex Transm Dis. 2005;32(11):685-90.

16. Go VF, Solomon S, Srikrishnan AK, Sivaram S, Johnson SC, et al. HIV rates and risk behaviors are low in the general population of men in Southern India but high in alcohol venues: results from 2 probability surveys. J Acquir Immune Defic Syndr. 2007;46:491-7.

17. NACO. National Behavioural Survillance Survey (BSS) 2006: men who have sex with Men and Injecting Drug Users. New Delhi: Ministry of Health \& Family Welfare; 2006.

18. Mimiaga MJ, Thomas B, Mayer KH, Reisner SL, Menon S, et al. Alcohol use and HIV sexual risk among MSM in Chennai, India. Int J STD AIDS. 2011;22:121-5.

19. Go VF, Srikrishnan AK, Sivaram S, Murugavel GK, Galai N, et al. High HIV prevalence and risk behaviors in men who have sex with men in Chennai, India. J Acquir Immune Defic Syndr. 2004;35:314-9.

20. Thomas B, Mimiaga MJ, Menon S, Chandrasekaran V, Murugesan $\mathrm{P}$, et al. Unseen and unheard: predictors of sexual risk behavior and HIV infection among men who have sex with men in Chennai, India. AIDS Educ Prev. 2009;21:372-83.

21. Newman PA, Chakrapani V, Cook C, Shunmugam M, Kakinami L. Determinants of sexual risk behavior among men who have sex with men accessing public sex environments in Chennai, India. J LGBT Health Res. 2008;4:81-7.

22. Chakrapani V, Boyce P, Newman PA, Row Kavi A. Contextual influences on condom use among men who have sex with men in India: subjectivities, practices and risks. Cult Health Sex. 2013;15:938-51.

23. Chakrapani V, Newman PA, Shunmugam M. Secondary HIV prevention among kothi-identified MSM in Chennai, India. Cult Health Sex. 2008;10:313-27.

24. Mimiaga MJ, Biello KB, Sivasubramanian M, Mayer KH, Anand VR, et al. Psychosocial risk factors for HIV sexual risk among Indian men who have sex with men. AIDS Care. 2013;25(9):1109-13.

25. Saidel T, Adhikary R, Mainkar M, Dale J, Loo V, et al. Baseline integrated behavioural and biological assessment among most atrisk populations in six high-prevalence states of India: design and implementation challenges. AIDS. 2008;22(Suppl 5):S17-34.

26. Chandrasekaran P, Dallabetta G, Loo V, Mills S, Saidel T, et al. Evaluation design for large-scale HIV prevention programmes: the case of Avahan, the India AIDS initiative. AIDS. 2008;22(Suppl 5):S1-15

27. MacKellar DA, Gallagher KM, Finlayson T, Sanchez T, Lansky A, et al. Surveillance of HIV risk and prevention behaviors of men who have sex with men-a national application of venue-based, time-space sampling. Public Health Rep. 2007;122(Suppl 1): $39-47$.

28. Semaan S, Lauby J, Liebman J. Street and network sampling in evaluation studies of HIV risk-reduction interventions. AIDS Rev. 2002;4:213-23.

29. Brahmam GN, Kodavalla V, Rajkumar H, Rachakulla HK, Kallam S, et al. Sexual practices, HIV and sexually transmitted infections among self-identified men who have sex with men in 
four high HIV prevalence states of India. AIDS. 2008;22(Suppl 5):S45-57.

30. WHO. The alcohol use disorders identification test guidelines for use in primary care. Geneva: World Health Organization; 2001. p. 41.

31. Nandi J, Kamat H, Bhavalkar V, Banerjee K. Detection of human immunodeficiency virus antibody among homosexual men from Bombay. Sex Transm Dis. 1994;21:235-6.

32. Asthana S, Oostvogels R. The social construction of male 'homosexuality' in India: implications for HIV transmission and prevention. Soc Sci Med. 2001;52:707-21.

33. UNAIDS. India MSM country snapshots-country specific information on HIV, men who have sex with men (MSM) and transgender people (TG). New Delhi: UNAIDS; 2010.

34. StataCorp. Stata Statistical Software: Release 12. College Station, TX: StataCorp LP; 2009.

35. Boyce P, Chakrapani V, Dhanikachalam D. Hard-to-reach men who have sex with men in India recommendations for HIV prevention. New Delhi, India: NACO; 2011.

36. Aneshensel CS. Theory-based data analysis for the social sciences. Thousand Oaks, CA: SAGE Publications, Inc; 2013.

37. Neufeld KJ, Peters DH, Rani M, Bonu S, Brooner RK. Regular use of alcohol and tobacco in India and its association with age, gender, and poverty. Drug Alcohol Depend. 2005;77:283-91.

38. Singh RB, Beegom R, Mehta AS, Niaz MA, De AK, et al. Social class, coronary risk factors and undernutrition, a double burden of diseases, in women during transition, in five Indian cities. Int $\mathbf{J}$ Cardiol. 1999;69:139-47.

39. Mohan D, Chopra A, Sethi H. The co-occurrence of tobacco and alcohol in general population of metropolis Delhi. Indian J Med Res. 2002;116:150-4.

40. Greenwood GL, Paul JP, Pollack LM, Binson D, Catania JA, et al. Tobacco use and cessation among a household-based sample of US urban men who have sex with men. Am J Public Health. 2005;95:145-51.

41. Berg CJ, Nehl EJ, Wong FY, He N, Huang ZJ, et al. Prevalence and correlates of tobacco use among a sample of MSM in Shanghai, China. Nicotine Tob Res. 2011;13:22-8.

42. Sander PM, Cole SR, Stall RD, Jacobson LP, Eron JJ, et al. Joint effects of alcohol consumption and high-risk sexual behavior on HIV seroconversion among men who have sex with men. AIDS. 2013;27:815-23.
43. Hutton HE, McCaul ME, Chander G, Jenckes MW, Nollen C, et al. Alcohol use, anal sex, and other risky sexual behaviors among HIVinfected women and men. AIDS Behav. 2013;17:1694-704.

44. Heath J, Lanoye A, Maisto S. The role of alcohol and substance use in risky sexual behavior among older men who have sex with men: a review and critique of the current literature. AIDS Behav. 2012;16:578-89.

45. Mustanski B. Moderating effects of age on the alcohol and sexual risk taking association: an online daily diary study of men who have sex with men. AIDS Behav. 2008;12:118-26.

46. Chakrapani V, Boyce P, Dhanikachalam D. Women partners of men who have sex with men in India. India 'MSM situation paper' series-Technical Brief 2. India: DFID AIDS Technical Assistance Support Team (of Futures Group International Pvt. Ltd., India) for National AIDS Control Organisation (NACO); 2011.

47. Saggurti N, Mishra RM, Proddutoor L, Tucker S, Kovvali D, et al. Community collectivization and its association with consistent condom use and STI treatment-seeking behaviors among female sex workers and high-risk men who have sex with men/transgenders in Andhra Pradesh, India. AIDS Care. 2013;25:S55-66.

48. Chakrapani V, Newman PA, Shunmugam M, McLuckie A, Melwin F. Structural violence against Kothi-identified men who have sex with men in Chennai, India: a qualitative investigation. AIDS Educ Prev. 2007;19:346-64.

49. Newman PA, Chakrapani V, Cook C, Shunmugam M, Kakinami L. Correlates of paid sex among men who have sex with men in Chennai, India. Sex Transm Infect. 2008;84:434-8.

50. Goswami P, Rachakulla HK, Ramakrishnan L, Mathew S, Ramanathan S, et al. An assessment of a large-scale HIV prevention programme for high-risk men who have sex with men and transgenders in Andhra Pradesh, India: using data from routine programme monitoring and repeated cross-sectional surveys. BMJ Open. 2013. doi:10.1136/bmjopen-2012-002183.

51. Magnani R, Sabin K, Saidel T, Heckathorn D. Review of sampling hard-to-reach and hidden populations for HIV surveillance. AIDS. 2005;19(Suppl 2):S67-72.

52. Luchters S, Geibel S, Syengo M, Lango D, King'ola N, et al. Use of AUDIT, and measures of drinking frequency and patterns to detect associations between alcohol and sexual behaviour in male sex workers in Kenya. BMC Public Health. 2011;11:384. 